\title{
VITILIGO AND HELMINTHIASIS- A RETROSPECTIVE STUDY TO ESTABLISH A CAUSAL RELATIONSHIP IN PATIENTS TREATED WITH CODED UNANI DRUG
}

\author{
Mohd Adil'1, Ishrat Jaha Khan'2, Irfan Ahmad³, Masroor A. Qureshi', Nirmala Devi' ${ }^{5}$, Haseeb Alam Lari 6 \\ ${ }^{1}$ Research Officer, Department of Biochemistry, Regional Research Institute of Unani Medicine, Mumbai, Maharashtra, India. \\ ${ }^{2}$ Laboratory Technician, Department of Biochemistry, Regional Research Institute of Unani Medicine, Mumbai, Maharashtra, India. \\ ${ }^{3}$ Research Officer, Department of Unani, Regional Research Institute of Unani Medicine, Mumbai, Maharashtra, India. \\ ${ }^{4}$ Research Officer, Department of Unani, Regional Research Institute of Unani Medicine, Mumbai, Maharashtra, India. \\ ${ }^{5}$ Research Officer, Department of Pathology, Regional Research Institute of Unani Medicine, Mumbai, Maharashtra, India. \\ ${ }^{6}$ Research Officer, Department of Unani, Regional Research Institute of Unani Medicine, Mumbai, Maharashtra, India.
}

\begin{abstract}
BACKGROUND

Vitiligo is a de-pigmenting disorder characterized by the development of white patches in various distributions, which are due to the loss of melanocytes from the epidermis. More than 150 million people worldwide suffer from vitiligo. No country is immune, although each has different prevalence rates. India shows the highest incidence in the world (up to $8.8 \%$ ). [2] However, it is difficult to get a true picture of the prevalence of vitiligo. The largest epidemiological study of the prevalence of vitiligo is based on 47,033 inhabitants of the island of Bornholm in Denmark, showing an incidence of $0.38 \%$. Though vitiligo can develop at any age, in $70 \%$ to $80 \%$ cases, it arises before the age of 30 . Absence of melanocytes in the skin lesion due to their destruction has been suggested to be the key event in the pathogenesis of vitiligo. Non-segmental vitiligo (NSV) results from autoimmune destruction of melanocytes. The altered levels of various cytokines have been proposed in the pathogenesis of vitiligo. Etiopathogenesis of this disorder is not fully understood. The trigger for development of autoimmune reaction against melanocytes is still under study. However, the exact immune mechanisms have not yet been fully elucidated. We wanted to investigate the frequency of intestinal parasitic infestation in cases of vitiligo and to establish aetiopathological relationship if any.
\end{abstract}

\section{METHODS}

Laboratory reports of a total of 160 Vitiligo patients enrolled at Regional Research Institute of Unani Medicine, Mumbai for treatment with coded unani medicine were analysed retrospectively. Patients with vitiligo treated in Out Patient Department of Regional Research Institute of Unani Medicine, Mumbai are investigated for complete blood count (CBC), complete liver function tests (cLFT), stool examination for ova/cyst and complete renal function test. Data of RRIUM Laboratory was collected and analysed retrospectively. Reports of Stool examination done on two consecutive days in all patients treated with coded Unani drug before administering the trial medicine were analysed. Data of patients enrolled for treatment for over a period of three years was collected and analysed retrospectively.

\section{RESULTS}

Out of 160 patients with Vitiligo, $133(83.12 \%)$ were positive for intestinal parasites confirmed by faecal examination on two consecutive days out of which, 64 (48.12\%) for Ascaris lumbricoides, 55 (41.35\%) for Tapeworm, 14 (10.52 \%) for mixed infection. Stool examination of 27 (16.87\%) patients did not show intestinal helminthiasis. The data was collected and analysed retrospectively. The Data was statically analysed using Karl Pearson's Coefficient Correlation method which shows significance at $95 \%$ C.I, p $<0.05$

\section{CONCLUSIONS}

The pathogenesis of vitiligo, though, partially understood still remains complex and enigmatic to a great extent. However, the presented scientific approaches in recent years have yielded some interesting clues giving credence to both oxidative stress and autoimmune hypotheses with potential clinical relevance. Although the condition may be precipitated by multiple aetiologies, the interaction of oxidative stress with immune system clearly appears to be the key convergent pathway that initiates and/or amplifies the enigmatic loss of melanocytes. Parasitic infection and host parasite interaction may be a factor which triggers the autoi mmune destruction of melanocytes. Further study to show the variation in cytokines and inflammatory markers concentration and their interaction with oxidative stress and immune system of vitiligo patients with helminthiasis is to be carried out to establish the aetiopathological correlation of vitiligo and helminthiasis. Based on the above results and discussion, it can be concluded that intestinal helminthiasis may have an active role in vitiligo development and in its pathogenesis and may also act as an index of disease severity. The suggested role of helminthiasis in vitiligo development is not studied and its exact effect is not fully certain. More studies on a large scale of vitiligo patients are needed to confirm our results.

\section{KEY WORDS}

Vitiligo, Helminthiasis, Etiopathogenesis

HOW TO CITE THIS ARTICLE: Adil M, Khan IJ, Ahmad I, et al. Vitiligo and helminthiasis-a retrospective study to establish a causal relationship in patients treated with coded unani drug. J. Evolution Med. Dent. Sci. 2019;8(27):2209-2212, D0I: $10.14260 /$ jemds/2019/483. 
'Financial or Other Competing Interest': None.

Submission 30-03-2019, Peer Review 20-06-2019,

Acceptance 27-06-2019, Published 08-07-2019.

Corresponding Author:

Mohd Adil,

Research Officer

Department of Biochemistry,

RRIUM, JJ Hospital Compound,

Byculla, Mumbai,

Maharashtra, India.

E-mail: adiladi51@yahoo.com

DOI: $10.14260 /$ jemds/2019/483

\section{(c) $($ ) $\$$}

\section{BACKGROUND}

Vitiligo is a common dermatological disorder of the epidermis and hair follicles, manifesting clinically as expanding hypopigmented lesions of the skin. More than 150 million people worldwide suffer from vitiligo. No country is immune, although each has different prevalence rates.[1] India shows the highest incidence in the world (Up to $8.8 \% .^{[2]}$ However, it is difficult to get a true picture of the prevalence of vitiligo. The largest epidemiological study of the prevalence of vitiligo is based on 47,033 inhabitants of the island of Bornholm in Denmark, showing an incidence of $0.38 \%$. [3] Though vitiligo can develop at any age but in $70 \%$ to $80 \%$ cases, it arises before the age of 30.[4] Absence of melanocytes in the skin lesion due to their destruction has been suggested to be the key event in the pathogenesis of vitiligo.[5] The aetiology of vitiligo remains obscure despite being in focused debate for the last six decades. ${ }^{[5-9]}$ Hence, it is important to unravel the underlying etiologic mechanisms of vitiligo. A single dominant pathway appears unlikely to account for all cases of melanocyte loss in vitiligo, and apparently, a complex interaction between genetic, environmental, biochemical and immunological events is likely to generate a permissive milieu (Fig. 1). Loss of melanocytes in vitiligo appears to occur through a combination of several mechanisms that act in concert. Here, we discuss the possible mechanism and its interconnections with oxidative stress and immune system that are involved in melanocyte loss. There might be alteration in melanocyte-specific proteins by the action of reactive oxygen species (ROS), which results in the generation of neoantigens, autoimmunity and melanocytophagy leading to apoptosis.

Interplay of genes, environment and immune system may lead to depletion of melanocyte and precipitation of vitiligo. In relation to this, it is known that vitiligo is frequently associated with several other autoimmune diseases including uveitis,[10] diabetes mellitus,[11] and autoimmune thyroid disease ${ }^{[12]}$ and atrophic gastritis, ${ }^{[13]}$ several positive human leukocyte antigen (HLA)-association for vitiligo have been reported. HLA-A2, HLADw7,[14] HLA-DR4, [14-16] B13, Bw35, [17] Cw7, and DR6.

\section{Aims and Objectives}

To investigate the frequency of intestinal parasitic infestation in cases of vitiligo and to establish any aetiopathological relationship.

\section{METHODS}

This study is based on retrospective analysis of the laboratory data of patients obtained from research laboratory of Regional Research Institute of Unani Medicine; Mumbai treated with UNANI coded Drugs UNIM 04 and UNIM 05 for vitiligo. Ethical clearance was obtained from institute ethical committee for retrospective analysis of data of 160 patients obtained during the treatment of vitiligo attending the posttrial access (PTA) OPD of Regional Research Institute of Unani Medicine, Mumbai. This retrospective study was carried out using laboratory data spread out for three years April 2012 to March 2015. Complete Blood Count (CBC), Complete Liver Function Tests (cLFT), and stool examination for Ova/ Cyst; and Renal Function Test were done routinely in all patients enrolled for treatment of vitiligo.

Laboratory reports of total 160 Vitiligo patients enrolled at Regional Research Institute of Unani Medicine, Mumbai for treatment with coded unani medicine was analysed retrospectively. Sample size was taken based on the convenience of the study.

Patients with vitiligo treated in Out Patient Department of Regional Research Institute of Unani Medicine, Mumbai are investigated for complete Blood count (CBC), complete liver function tests (CLFT), and stool examination for ova/cyst; and complete renal function test are done routinely.

\section{Stool Examination}

Thin emulsion of faecal matter in a drop of normal saline placed on glass slide and covered with cover slip to be examined under microscope. Iodine preparation was done to confirm the morphology of ova and cysts Lugol's iodine was used in place of saline. The iodine stains the cysts especially the nuclear structure thus making identification possible.

\section{Statistical Methods}

The statistical package for social science $\{$ SPSS $\}$ version 20 will be used for data analysis. Mean, median, and SD are used to describe quantitative data. Qualitative data are summarized using frequency and percentage.

\section{RESULTS}

We have studied 160 patients and found out 133 that are 83.12 $\%$ patients were positive (With Helminthiasis) and 27 patients were negative (Without Helminthiasis).

\begin{tabular}{|c|c|c|c|}
\hline Age in Years & Male & Female & Total \\
\hline $15-25$ & $37(45.12 \%)$ & $45(54.9 \%)$ & 82 \\
\hline $25-35$ & $33(62.26 \%)$ & $20(37.7 \%)$ & 53 \\
\hline $35-45$ & $14(60.86 \%)$ & $09(39.13 \%)$ & 23 \\
\hline $45-55$ & 01 & 01 & 02 \\
\hline $55-65$ &.. &.. &.. \\
\hline Total & 85 ( 53.12 \% ) & $\mathbf{7 5}(\mathbf{4 6 . 8 7} \%)$ & $\mathbf{1 6 0}$ \\
\hline \multicolumn{4}{|c}{ Table 1. Age and Sex Wise Distribution } \\
\hline
\end{tabular}

\begin{tabular}{|c|c|c|c|}
\hline $\begin{array}{c}\text { Age Wise Worm } \\
\text { Infection in Leucoderma }\end{array}$ & $\begin{array}{c}\text { Vitiligo with } \\
\text { Helminthiasis }\end{array}$ & $\begin{array}{c}\text { Vitiligo without } \\
\text { Helminthiasis }\end{array}$ & Total \\
\hline $15-25$ & $69(84.14 \%)$ & 13 & $\mathbf{8 2}$ \\
\hline $25-35$ & $41(78.84 \%)$ & 11 & $\mathbf{5 2}$ \\
\hline $35-45$ & $23(95.83 \%)$ & 01 & $\mathbf{2 4}$ \\
\hline $45-55$ & 0 & 02 & $\mathbf{0 2}$ \\
\hline $55-65$ & 0 & 00 & $\mathbf{0 0}$ \\
\hline Total & $\mathbf{1 3 3}(83.12 \%)$ & $\mathbf{2 7}(16.87 \%)$ & $\mathbf{1 6 0}$ \\
\hline \multicolumn{4}{|c|}{ Table. 2 Age Wise Worm Infection in Vitiligo } \\
\hline
\end{tabular}

\begin{tabular}{|c|c|c|c|c|c|c|}
\hline $\begin{array}{c}\text { Diet } \\
\text { Habit }\end{array}$ & $\begin{array}{c}\text { Round } \\
\text { Worm }\end{array}$ & $\begin{array}{c}\text { Tape } \\
\text { Worm }\end{array}$ & Giardia & $\begin{array}{c}\text { Entamoeba } \\
\text { Histolytica }\end{array}$ & NAD & Total \\
\hline Vegetarian & 37 & 04 & 05 & 02 & 14 & $\begin{array}{c}62 \\
(38.75 \%)\end{array}$ \\
\hline $\begin{array}{c}\text { Non - } \\
\text { vegetarian }\end{array}$ & 23 & 51 & 06 & 05 & 13 & $\begin{array}{c}98 \\
(61.25 \%)\end{array}$ \\
\hline Total & $\begin{array}{c}\mathbf{6 0} \\
(\mathbf{3 7 . 5 \% )}\end{array}$ & $\begin{array}{c}\mathbf{5 5} \\
(\mathbf{3 4 . 3 7 \% )}\end{array}$ & $\mathbf{1 1}$ & $\mathbf{0 7}$ & $\begin{array}{c}\mathbf{2 7} \\
(\mathbf{1 6 . 8 7 \%})\end{array}$ & 160 \\
\hline \multicolumn{7}{|c|}{ Table 3. Diet Wise Distributions } \\
\hline
\end{tabular}




\section{Magnitude of Problem by Simple Vertical Bar Chart}

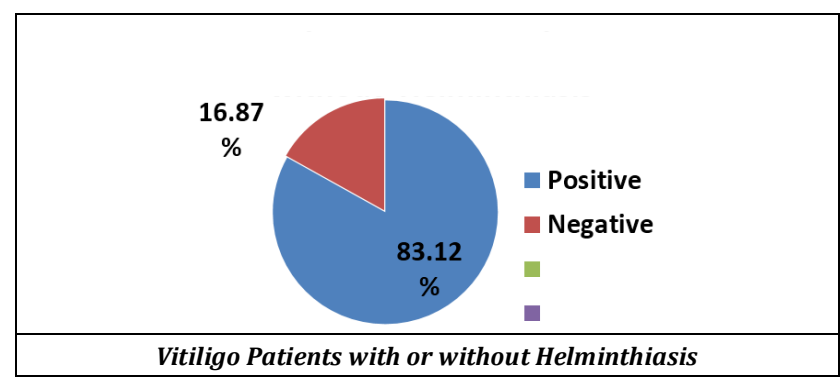

Magnitude of Problem by Pie Chart Percentage Value Types of Helminthiasis Found in Vitiligo Patients

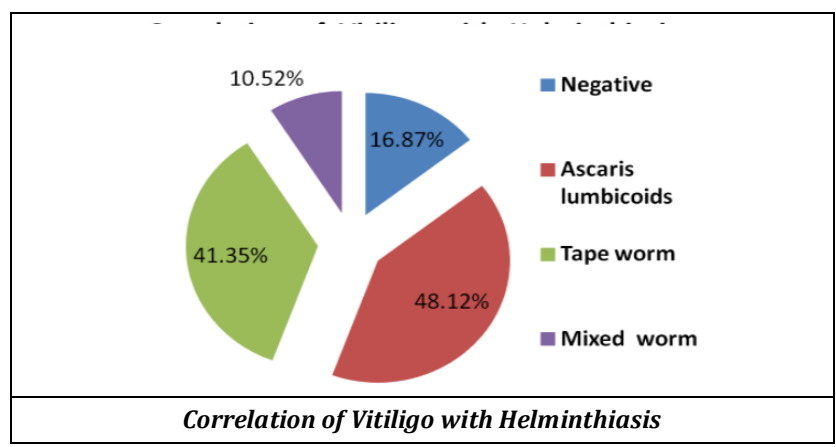

In the present study (Table no. 1) of Vitiligo patients, we observed that $(53.12 \%)$ of patients registered in the span of 3 years were Male $(n=85)$ and $(46.87 \%)$ of patients registered were Female $(n=75)$. Disease predominance was observed in the age group of 25 - 35 years in Male (62.26) and 15 - 25 years in female is (54.9\%).

As per the Table no. 2, we observed that out of total number of patients $(n=160)$ during the retrospective analysis, $83.12 \%(\mathrm{n}=133)$ subjects were having helminthic infection $(16.87 \%(n=27)$ were showing no helminthic infection.

Observation made based on the dietary habits of the patients with helminthiasis (Table 3$)$ shows that $\mathrm{n}=62(38.75$ $\%$ ) of patients were following Vegetarian Diet and $n=98$ (61.25\%) were following Non-vegetarian Diet.

Ascaris lumbricoides infection was observed in $\mathrm{n}=60$ $(37.5 \%)$ of patients and $n=55(34.37 \%)$ were Tape worm infection. Predominance of Ascaris lumbricoides infection and $\mathrm{n}=18$ patients of Giardia and Entamoeba histolytica infection was observed in vitiligo patients irrespective of their dietry preferences.

The Karl Pearson's Coefficient Correlation between two variables Vitiligo \& Helminthiasis is + 1.003174.The correlation coefficient is positive, above 1 value. There is strong positive correlation between Vitiligo \& Helminthiasis. It indicates that Vitiligo may be commonly associated with Helminthiasis. Helminthiasis is a causative factor in the development of Vitiligo.

\section{DISCUSSION}

Despite efforts to precisely pinpoint the exact cause of vitiligo, no breakthrough has been achieved. The present study has thus made another attempt to shed some light on the disease. Increased incidence of intestinal parasitic infection was observed in retrospective analysis of laboratory data obtained from patients investigated during treatment of vitiligo. Parasitic infection and host parasite interaction may be a factor which triggers the autoimmune destruction of melanocytes.

Some cytokines that are stereotypically produced in response to gastrointestinal nematode infections fail to enhance host protection against some of the parasites that elicit their production. Host protection is redundant at two levels: 1 . IL - 4 has multiple effects on the immune system and on gut physiology), more than one of which may protect against a particular parasite; and 2. IL - 4 is often only one of multiple stimuli that can induce protection. Hosts may have evolved the ability to recognize features that characterize parasitic gastrointestinal nematodes as a class as triggers for a stereotypic cytokine response, but not the ability to distinguish features of individual parasites as stimuli for more specific protective cytokine responses. As a result, hosts deploy a set of defence mechanisms against these parasites that together control infection by most members of that class, even though a specific defence mechanism may not be required to defend against a particular parasite and may even damage a host infected with that parasite.

Further study to show the variation in cytokines and inflammatory markers concentration and their interaction with oxidative stress and immune system of vitiligo patients with helminthiasis is to be carried out to establish the aetiopathological correlation of vitiligo and helminthiasis. Based on the above results and discussion, that intestinal helminthiasis may have an active role in vitiligo development and in its pathogenesis, and may also act as an index of disease severity. The suggested role of helminthiasis in vitiligo development is not studied and its exact effect is not fully certain. More studies on a large scale of vitiligo patients to confirm our results.

\section{CONCLUSIONS}

The pathogenesis of vitiligo, though, partially understood still remains complex and enigmatic to a great extent. However, the presented scientific approaches in recent years have yielded some interesting clues giving credence to both oxidative stress and autoimmune hypotheses with potential clinical relevance. Although the condition may be precipitated by multiple aetiologies, the interaction of oxidative stress with immune system clearly appears to be the key convergent pathway that initiates and/or amplifies the enigmatic loss of melanocytes. Parasitic infection and host parasite interaction may be a factor which triggers the autoimmune destruction of melanocytes. Further study to show the variation in cytokines and inflammatory markers concentration and their interaction with oxidative stress and immune system of vitiligo patients with helminthiasis is to be carried out to establish the aetiopathological correlation of vitiligo and helminthiasis. Based on the above results and discussion, it can be concluded that intestinal helminthiasis may have an active role in vitiligo development and in its pathogenesis and may also act as an index of disease severity. The suggested role of helminthiasis in vitiligo development is not studied and its exact effect is not fully certain. More studies on a large scale of vitiligo patients are needed to confirm our results. 


\section{REFERENCES}

[1] Kruger C, Schallreuter KU. A review of the worldwide prevalence of vitiligo in children/ adolescents and adults. Int J Dermatol 2012;51(10):1206-12.

[2] Behl PN, Bhatia RK. 400 cases of vitiligo: a clinicotherapeutic analysis. Indian J Dermatol 1972;17(2):516.

[3] Howitz J, Brodthagen H, Schwartz M, et al. Prevalence of vitiligo. Epidemiological survey on the Isle of Bornholm, Denmark. Arch Dermatol 1977;113(1):4752.

[4] Alikhan A, Felsten LM, Daly M, et al. Vitiligo: a comprehensive overview Part I. Introduction, epidemiology, quality of life, diagnosis, differential diagnosis, associations, histopathology, etiology and work - up. J Am Acad Dermatol 2011;65(3):473-91.

[5] Le Poole IC, Das PK, Van Den Wijngaard RM, et al. Review of the etiopathomechanism of vitiligo: a convergence theory. Exp Dermatol 1993;2(4):145-53.

[6] Taieb A. Intrinsic and extrinsic pathomechanisms in vitiligo. Pigment Cell Res 2000;13(Suppl 8):41-7.

[7] Ortonne JP, Bose SK. Vitiligo: Where do we stand? Pigment Cell Res 1993;6(2):61-72.

[8] Shajil EM, Chatterjee S, Agrawal D, et al. Vitiligo: pathomechanisms and genetic polymorphism of susceptible genes. Indian J of Exp Biol 2006;44(7):52639.
[9] Park S, Albert DM, Bolognia JL. Ocular manifestations of pigmentary disorders. Dermatol Clin 1992;10(3):60922.

[10] Gould IM, Gray RS, Urbaniak SJ, et al. Vitiligo in diabetes mellitus. Br J Dermatol 1985;113(2):153-5.

[11] Hegedus L, Heidenheim M, Gervil M, et al. High frequency of thyroid dysfunction in patients with vitiligo. Acta Derm Venereol 1994;74(2):120-3.

[12] Zauli D, Tosti A, Biasco G, et al. Prevalence of autoimmune atrophic gastritis in vitiligo. Digestion 1986;34(3):169-72.

[13] Buc M, Busova B, Hegyi E, et al. Vitiligo is associated with HLA-A2 and HLA-Dw7 in the Slovak populations. Folia Biol (Praha) 1996;42(1-2):23-5.

[14] Dunston GM, Halder RM. Vitiligo is associated with HLA-DR4 in black patients: a preliminary report. Arch Dermatol 1990;126(1):56-60.

[15] Foley LM, Lowe NJ, Misheloff E, et al. Association of HLA-DR4 with vitiligo. J Am Acad Dermatol 1983;8(1):39-40.

[16] Metzker A, Zamir R, Gazit E, et al. Vitiligo and the HLA system. Dermatologica 1980;160(2):100-5.

[17] Venneker GT, de Waal LP, Westerhof W, et al. HLA associations in vitiligo patients in the Dutch population. Dis Markers 1993;11(4):187-90. 